\title{
BMJ Open Odds of return: a prospective study using provider assessment to predict short-term patient return visits to the emergency department
}

\author{
Scott Fruhan, ${ }^{1}$ Corey B Bills (D) ${ }^{2}$
}

To cite: Fruhan S, Bills CB. Odds of return: a prospective study using provider assessment to predict short-term patient return visits to the emergency department. BMJ Open 2021;11:e053918. doi:10.1136/ bmjopen-2021-053918

- Prepublication history and additional supplemental material for this paper are available online. To view these files, please visit the journal online (http://dx.doi.org/10.1136/ bmjopen-2021-053918).

Received 03 June 2021 Accepted 27 October 2021

A) Check for updates

(C) Author(s) (or their employer(s)) 2021. Re-use permitted under CC BY-NC. No commercial re-use. See rights and permissions. Published by BMJ.

${ }^{1}$ Department of Emergency Medicine, University of California San Francisco, San Francisco, California, USA

${ }^{2}$ Department of Emergency Medicine, University of Colorado Denver School of Medicine, Aurora, Colorado, USA

Correspondence to

Dr Corey B Bills;

corey.bills@cuanschutz.edu

\section{ABSTRACT}

Objective Previous studies have assessed patient-level characteristics associated with emergency department (ED) return visits, but none have used provider assessment. We prospectively investigate whether clinical providers could accurately predict ED return visits.

Methods Prospective cohort study.

Setting Single academically affiliated urban county hospital.

Participants Discharged ED patients over a 14-month period with a provider assessment of the likelihood of patient return within 7 days of ED discharge.

Main outcome measures The primary outcome of interest was a return visit to the ED within 7 days. Additional outcome measures included a return visit within 72 hours and a return visit resulting in admission. We also measured the accuracy of provider gestalt, and provide measures of sensitivity, specificity, predictive values, and likelihood ratios.

Results of the 11922 ED discharges included in this study, providers expected $2116(17.7 \%)$ to result in a return visit within 7 days. Providers were much more likely to perceive a return visit if the patient left against medical advice (OR: 5.97, 95\% Cl: 4.67 to 7.62 ), or was homeless (OR: $5.69,95 \% \mathrm{Cl}: 5.14$ to 6.29$)$. Patients who actually returned were also more likely to be homeless, English speaking and to have left the ED against medical advice on the initial encounter. The strongest predictor of a return visit at both 72 hours and 7 days in multivariable modelling was provider assessment (OR: $3.77,95 \% \mathrm{Cl}$ : 3.25 to 4.37 ; OR: $3.72,95 \%$ Cl: 3.29 to 4.21 , respectively). Overall sensitivity and specificity of provider gestalt as a measure of patient return within 7 days were $47 \%$ and $87 \%$, respectively. The positive and negative likelihood ratios were 3.51 and 0.61 , respectively.

Conclusions Clinician assessment was the strongest predictor of a return visit in this dataset. Clinician assessment may be used as a way to screen patients during the index visit and enrol them in efforts to decrease return visits.

\section{INTRODUCTION}

Emergency department (ED) return visits following discharge represent a commonly used quality metric, as they are presumed to result from mistaken diagnoses, lack of

\section{Strengths and limitations of this study}

This is the first study to report on the predictive quality of medical provider gestalt in determining the likelihood of a patient's return to the emergency department (ED) after an initial index visit.

- Among multiple demographic, social and clinical variables, the strongest predictor of the overall odds of return to the ED within 7 days of an initial visit was provider assessment.

- Generalisability may be challenging given the sampling frame and non-random nature of the study.

complete ED care, missed opportunities for provision of additional services or social needs, or lack of appropriate follow-up. In order to design effective interventions to mitigate the resource utilisation and potential harm associated with multiple ED visits, healthcare systems must first improve their ability to predict unplanned return visits prior to the initial discharge of patients.

Numerous studies have sought to identify predictors both of revisits to the $\mathrm{ED}^{1-3}$ and of revisits resulting in hospital admission. ${ }^{4-6}$ While several variables, including demographics such as older age, social factors such as homelessness, high-risk dispositions such as leaving against medical advice (AMA), and certain chronic medical conditions, have all been found to confer some risk of return after an initial ED visit, no tools currently exist to predict this outcome with a high level of accuracy. ${ }^{12}$ Similarly, no prior studies have investigated the use of provider assessment (ie, gestalt) to determine a patient's risk of return.

Provider assessment has previously been used to evaluate the medical risks associated with a number of ED patient presentations, with variable results. Prior literature has weighed the degree to which providers can accurately predict patients at risk of suicide, ${ }^{7}$ 
opioid use or misuse, ${ }^{8}$ and high-risk medical events such as acute coronary syndrome ${ }^{9}$ and pulmonary embolism. ${ }^{10}$ The Wells' criteria for risk of pulmonary embolism, currently in broad use in clinical emergency medicine, demonstrate a successful incorporation of provider gestalt. $^{10}$

The aim of this study was to investigate how accurately a binary gestalt opinion from the treating clinical provider could predict an ED return visit, either alone or in concert with other objective patient characteristics. The more accurately this category of patients can be identified in advance, the more effective potential targeted interventions can be.

\section{MATERIALS AND METHODS}

We conducted a prospective cohort study of discharged patients from a single, urban, academically affiliated county hospital in California over a 14-month period from January 2018 through February 2019. Over the study period, clinical providers responsible for the care and disposition of each patient had the opportunity to predict whether a patient discharged from the ED was 'more likely than average to return' to the ED within 7 days of the index visit. Clinical providers were defined as attending level physicians, residents (from various specialties) and advanced practice providers.

'More likely than average to return' was defined as whether the provider perceived an increased risk of return to the ED in the proceeding 7 days after the index visit and was categorised as a simple 'yes' or 'no'. 'More likely than average' was based on provider gestalt and defined in comparison with the historical baseline return rate of approximately $13 \%$ (based on internal quality metrics). Providers were exposed to an extensive education campaign, including meetings, posters and emails, explaining the study design and that the baseline average likelihood of 7-day ED return was 13\% over the previous 12 months. Providers received no additional training on the topic other than how to fill in the answer via the electronic health record (EHR).

A screening prompt ('RTED 7-day risk $>13 \%$ ?') was embedded in the discharge tab of the patient's ED EHR. Due to limitations of the EHR, we could not provide additional text. The provider's answer was directly entered into the electronic medical system during the discharge via a 'yes-no' radio button following the above prompt. Answering this specific question on discharge was voluntary, did not preclude a patient's final disposition and did not become part of the medical record.

All patients discharged from the ED with a recorded provider assessment of return likelihood, including those who left AMA or those absent on eventual discharge, were included in the study.

Patients were excluded from analysis if, during the study period, the provider did not assess the patient's risk of return. Index visits resulting in a death in the ED were also excluded, as were visits resulting in a hospital admission, transfer to another facility (including to another hospital for admission, jail or prison, to urgent care or psychiatric emergency services), or duplicate encounters, and visits in which the patient presented but left without being triaged or seen by a provider.

\section{Patient and public involvement}

Patients or the public were not involved in the design, or conduct, or reporting, or dissemination plans of our research.

\section{Outcome measures}

The primary outcome measure was a return visit to the ED within 7 days after the initial ED discharge. Secondary measures included whether the return visit resulted in an unscheduled visit within 72 hours and hospital admission. We report both the 72-hour and 7-day time frames given the lack of consensus from prior studies on adverse events after ED discharge, and the lack of an agreed-upon quality metric. ${ }^{11-15}$ The measurement of return visits was limited to the single department under study, and as such does not account for the risk of return to any other ED.

\section{Predictive characteristics}

We assessed visit-level demographic information including age, sex, race/ethnicity (white, black/African American, Hispanic, Asian, American Indian/Alaskan Native, Native Hawaiian/Pacific Islander and other), insurance status (private, self-pay/uninsured, Medicaid, Medicare and other), language preference, homeless (yes or no) and access to a personal phone (yes or no). We also collected information on prior visits, including the total number of prior visits and the number of visits within 180 days of the index visit.

We created a dichotomous variable based on mode of arrival and whether or not patients presented by ambulance. Length of stay in the ED was calculated and presented in minutes and later made a categorical variable based on median length of stay. Discharge disposition was also included with a dichotomous variable created to differentiate those who left the ED AMA or were absent on discharge from those who were discharged. We also collected the primary discharge diagnosis and aggregated diagnoses based on a previously described organ system classification. $^{16}$

\section{Statistical analysis}

We present overall numbers and percentages of all ED visits, as well as those meeting inclusion criteria. Initial comparisons of patient characteristics among those encounters perceived by providers to be more likely to result in a return with those perceived to be less likely were made using the Mantel-Haenszel summary $\mathrm{X}^{2}$ with univariable ORs presented to measure the strength of the relationship.

Univariable modelling was performed on patient characteristics and the presence or absence of an actual return visit within 72 hours and 7 days. A multivariable model was constructed with predictor variables chosen 
from univariable analysis if the $\mathrm{p}$ value was $<0.10$ and via purposeful variable selection, based on historical significance as confounders, including notable clinical, socioeconomic predictors and provider assessment. ${ }^{17}$ Other variables, while significant in univariable modelling, were eventually excluded owing to lack of good fit. In order to assess each model, we also calculated the area under the curve to assess for discrimination, Hosmer-Lemeshow statistics for goodness of fit and variance inflation factor statistics to assess for multicollinearity. Crude (unadjusted) and adjusted ORs and 95\% CIs were used to assess the associations of individual variables with risk of both 72-hour and 7-day return. We also compared individual patient visit characteristics and provider-assessed risk of return with return visits resulting in an unscheduled hospital admission. Given the presupposition that gestalt is positively correlated with experience, we also analysed the relationship between provider assessment and risk of return at 7 days, stratified by provider type.

In multivariable modelling, the unit of analysis was at the patient visit level. However, owing to the large number of patients who presented multiple times throughout the study, we controlled at the individual patient level as well.

Additional measures of the accuracy of provider gestalt, including sensitivity, specificity, predictive values and likelihood ratios, were also calculated. Data analyses were performed with Stata (StataCorp, College Station, Texas, USA).

\section{RESULTS}

Over the 14-month study period, there were 95447 unique visits to the ED (table 1). Patients were majority male $(\mathrm{N}=57411,60.2 \%)$, English speaking ( $\mathrm{N}=70514$, $77.1 \%)$ and had visited the ED at least once prior ( $\mathrm{N}=58$ $396,61.2 \%)$.

Of the 71342 patients discharged, left AMA and absent on eventual discharge, $10190(14.3 \%)$ returned to the ED within 7 days. A total of 11922 (16.7\%) patient encounters had a provider-assessed risk of return. These 11922 patient encounters included a total of 10113 unique patients seen.

Among 11922 patient encounters, the majority were male $(\mathrm{N}=7064,59.3 \%)$, non-white $(\mathrm{N}=9222,77.4 \%)$ and English speaking $(\mathrm{N}=8954,75.1 \%)$. For $45 \%(\mathrm{~N}=5322)$ of patients, this was their first visit to the study ED. Additionally, notable proportions were without a working phone $(\mathrm{N}=3312,27.8 \%)$, homeless $(\mathrm{N}=2793,23.4 \%)$, Hispanic $(\mathrm{N}=4258,35.7 \%)$ and had Medicaid insurance $(\mathrm{N}=6960$, $58.4 \%$, table 2).

Overall, providers predicted that $2116(17.7 \%$ of 11 922) discharged encounters were more likely than average to result in return within 7 days (table 3). Providers were much more likely to perceive a risk of return if the patient left AMA (OR: 5.97, 95\% CI: 4.67 to 7.62), was homeless (OR: 5.69, 95\% CI: 5.14 to 6.29 ), or had a primary psychiatric or substance use diagnosis (OR: 3.04, 95\% CI: 2.64 to 3.51). Providers' assessment of above-average risk of
Table 1 Patient demographic characteristics among total unique presentations and those with return to emergency department (ED) risk assessed ( $N=11$ 922) over the 14-month study period

\begin{tabular}{|c|c|c|}
\hline & $\begin{array}{l}\text { All patient } \\
\text { presentations }\end{array}$ & $\begin{array}{l}\text { Risk of return to } \\
\text { ED assessed }\end{array}$ \\
\hline Characteristic & $\mathrm{N}=95447(\%)$ & $\mathrm{N}=11922(\%)$ \\
\hline Median age (IQR) & $42(29-57)$ & $40(28-55)$ \\
\hline Female sex & $38035(39.8)$ & $4858(40.75)$ \\
\hline \multicolumn{3}{|l|}{ Preferred language } \\
\hline English & $70514(77.1)$ & $8954(75.1)$ \\
\hline Spanish & 16419 (17.9) & 2309 (19.4) \\
\hline Other & $4584(5.0)$ & $658(5.5)$ \\
\hline Working/listed phone & 85157 (89.2) & 8610 (72.2) \\
\hline
\end{tabular}

Number of visits in

180 days preceding

the index visit

$\begin{array}{ccc}0 & 37051(38.8) & 5322(44.6) \\ 1 & 27993(29.3) & 3150(26.4) \\ 2 & 10410(10.9) & 1200(10.1) \\ 3 & 5289(5.5) & 628(5.3) \\ 4+ & 14704(15.4) & 1622(13.6)\end{array}$

Number of historical

visits

\begin{tabular}{|c|c|c|}
\hline 0 & 37051 (38.8) & $5322(44.6)$ \\
\hline 1 & 11335 (11.9) & 1092 (9.2) \\
\hline 2 & $5648(5.9)$ & 625 (5.2) \\
\hline 3 & $4519(4.7)$ & $510(4.3)$ \\
\hline $4+$ & 36894 (38.7) & $4373(36.7)$ \\
\hline $\begin{array}{l}\text { Median length of stay } \\
\text { in ED minutes (IQR) }\end{array}$ & $259(148-416)$ & $249(160-373)$ \\
\hline
\end{tabular}

return was significantly associated with actual return to the ED within both 72 hours (OR: $6.05,95 \%$ CI: 5.29 to 6.93 ) and 7 days (OR: $5.86,95 \%$ CI: 5.23 to 6.56 ).

In sum, $1011(8.4 \%)$ and $1611(13.1 \%)$ patients with a recorded risk assessment returned to the ED within 72 hours and within 7 days of their index visit, respectively. The 7-day return rate among our sample was slightly less than the overall 7-day rate of return (14.3\%) for patients seen and discharged over the same time period. The risks of return within both 72 hours and within 7 days were assessed at the univariable level (table 4). Patients who returned within 7 days were over twice as likely to have left AMA or prior to discharge on the preceding encounter, be homeless, and be primarily English speaking. The strongest predictor of a return visit both within 72 hours and within 7 days was provider assessment (OR: $6.05,95 \%$ CI: 5.29 to 6.93 ; OR: $5.86,95 \%$ CI: 5.23 to 6.56 , respectively).

While attendings (OR: 6.16, 95\% CI: 5.11 to 7.44) provided a more accurate risk assessment than other providers, there was no significant statistical difference 
Table 2 Patient characteristics among unique patient encounters with return to emergency department (ED) risk assessed ( $\mathrm{N}=11$ 922) over the 14-month study period

\begin{tabular}{|c|c|}
\hline Characteristic & $\mathrm{N}=11922$ \\
\hline \multicolumn{2}{|l|}{ Race/ethnicity } \\
\hline White & $2700(22.7)$ \\
\hline Black & $2903(24.4)$ \\
\hline Hispanic & $4258(35.7)$ \\
\hline Asian & $1307(11.0)$ \\
\hline Native Hawaiian/Pacific Islander & $165(1.4)$ \\
\hline American Indian/Alaskan Native & $88(0.7)$ \\
\hline Other & $426(3.6)$ \\
\hline Unknown & $75(0.6)$ \\
\hline \multicolumn{2}{|l|}{ Insurance } \\
\hline Private & $889(7.5)$ \\
\hline Medicare & 1652 (13.9) \\
\hline Medicaid & $6960(58.4)$ \\
\hline Other public subsidised & $357(3.0)$ \\
\hline None & $1486(12.5)$ \\
\hline Other & $577(4.8)$ \\
\hline Homeless & $2793(23.4)$ \\
\hline Arrived by ambulance & $2641(22.2)$ \\
\hline \multicolumn{2}{|l|}{ Discharge diagnosis } \\
\hline Trauma & $2341(19.6)$ \\
\hline Abdominal pain & $1359(11.4)$ \\
\hline $\begin{array}{l}\text { Dyspnoea, cough, respiratory tract } \\
\text { infection }\end{array}$ & $1191(10.0)$ \\
\hline Atraumatic back and extremity pain & $1091(9.2)$ \\
\hline $\begin{array}{l}\text { Skin and soft tissue infection, } \\
\text { dermatological, allergic }\end{array}$ & $1024(8.6)$ \\
\hline Psychiatric, toxicological & $923(7.7)$ \\
\hline Genitourinary, gynaecological, obstetric & $854(7.2)$ \\
\hline Cardiac, chest pain & $798(6.7)$ \\
\hline Head, neck & $776(6.5)$ \\
\hline Other & $1565(13.1)$ \\
\hline Discharged from ED & 11652 (97.7) \\
\hline
\end{tabular}

between categories of provider with respect to their ability to predict return at 7 days (online supplemental table 1).

The association between characteristics of the index visit and a return visit within 72 hours and within 7 days was also assessed through conditional logistic regression (table 5). Provider-assessed risk was the strongest predictor of a return visit with an adjusted OR of 3.78 (95\% CI: 3.34 to 4.28). The odds of return among the homeless and those with at least one other visit in the last 180 days were twice as great as for domiciled patients, and for those patients who had no visits within the past 180 days (OR: $2.01,95 \%$ CI: 1.76 to 2.30 ; OR: $2.10,95 \%$
CI: 1.85 to 2.38 , respectively). The model's variable coefficients changed little when controlling for individual patients.

Of the 1611 visits resulting in eventual return to the ED within 7 days, $182(11.3 \%)$ were admitted to an inpatient service on the subsequent visit. The overall return visit rate resulting in hospital admission (among all patients included in the study) was $1.5 \%$ (182 out of 11 922). Characteristics including sex, race, insurance status or presentation by ambulance were similarly represented within revisits resulting in admission and revisits not resulting in admission.

The strongest predictors of hospital admission upon return were language and homelessness. English speakers were more likely to be admitted than non-English speakers (41 of 182, $22.5 \%$ vs 169 of $1429,11.8 \%, \mathrm{p}<0.0001$ ); and homeless patients were less likely to be admitted than domiciled patients (62 of 182, 34.1\% vs 732 of 1429 , $51.2 \%, \mathrm{p}<0.0001)$. Moreover, provider gestalt of the likelihood of revisit was not predictive of the revisit resulting in hospital admission (81 of 182, $44.5 \%$ vs 677 of 1429 , $47.4 \%, \mathrm{p}=0.465$ ).

Sensitivity and specificity of provider gestalt as a measure of patient return within 7 days were $47 \%$ and $87 \%$, respectively (online supplemental table 2). The positive and negative predictive values were $36 \%$ and $91 \%$, and overall accuracy was $82 \%$. The positive and negative likelihood ratios were 3.51 and 0.61 , respectively.

\section{DISCUSSION}

This study is the first to report on the predictive quality of medical provider gestalt in determining the likelihood of a patient's return to the ED after an initial index visit. Our results confirmed the hypothesised predictive ability of providers, and in fact showed it to be the single biggest predictor of the primary outcome. This study also reconfirmed many previously known demographic and clinical factors associated with ED revisits. A new incorporation of clinician gestalt as part of a patient's overall risk assessment for revisiting the ED may therefore be useful in addressing the growing problem of ED resource utilisation and could be used to direct resources toward mitigating patient return.

Patient revisits to the ED represent a significant strain on health systems in measurable ways. ${ }^{18}$ Revisits are associated with overcrowding, which has been shown to result in treatment delays and excessive mortality. ${ }^{19}{ }^{20}$ Emergency care is often more expensive than outpatient medicine, and revisits may therefore be an important contributor to overall health costs as well. ${ }^{21}$

Potential ED overuse is not a small problem. Previous data suggest that upwards of $40 \%$ of patients seek care more than once in an ED over a 2-year period. ${ }^{22}$ Reducing inappropriate ED revisits could reduce US healthcare spending by as much as $\$ 32$ billion each year. ${ }^{23-25}$ Although not the primary focus of the study, our data did reveal that over $13 \%$ of index visits resulted in a return 
Table 3 Demographic and differences in physician assessment of return risk regarding unique individual patient encounter

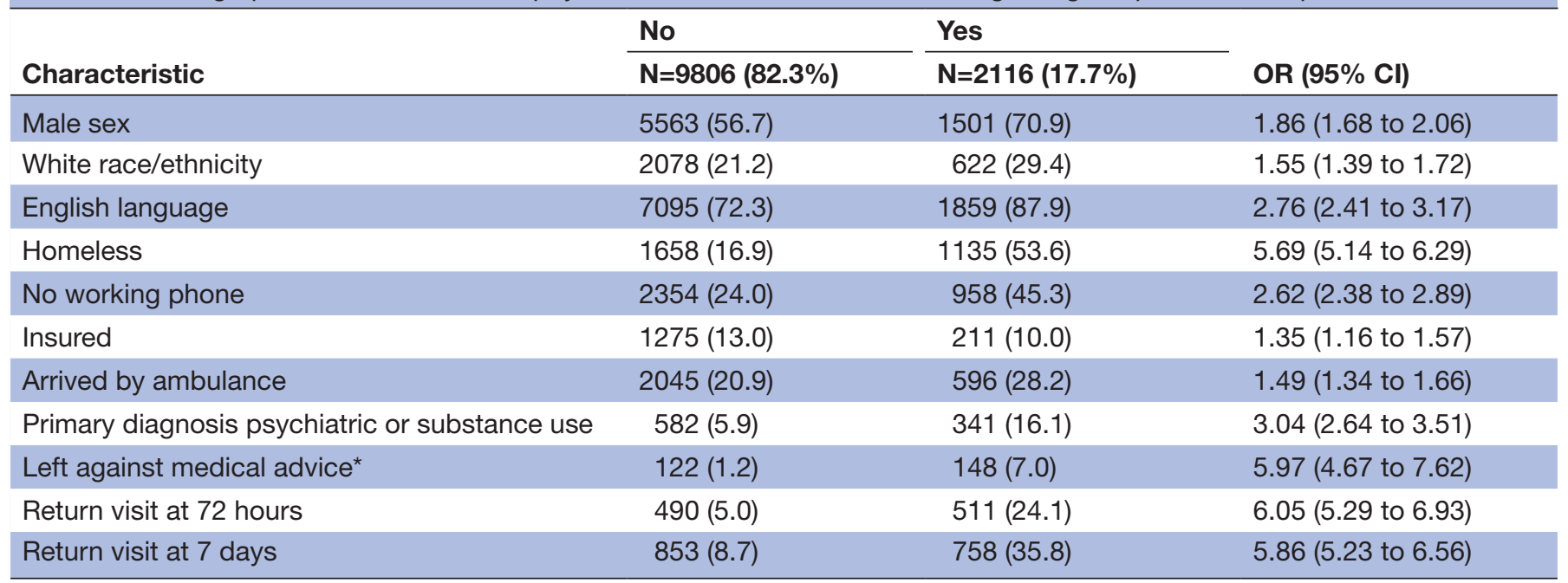

*Includes patients absent on eventual discharge

visit within 7 days, which provides a sense of the scale of opportunity for improvement.

The reduction of ED revisits has long been considered a measure of a successful discharge and a strategy for increasing care quality. ${ }^{26}$ Previous data suggest that multiple revisits may be avoidable, but developing effective strategies to reduce discharge failure requires better predictability of the patient population susceptible to it.

Past literature has elucidated many of the demographic and clinical variables associated with high rates of return. This study reconfirms some of these characteristics, in that homelessness, substance use, psychiatric illness and prior visits all confer substantially increased odds of ED revisit. ${ }^{27}$ Additional studies have attempted to combine these variables in predictive modelling. ${ }^{28}{ }^{29}$ While these previous models are useful, they lack the power of provider insight. To our knowledge, this is the first study to assess whether providers could holistically predict a patient's risk of return. In comparison with other patient variables, provider gestalt was the single greatest predictor of patient return after an index visit to the ED.

Providers are often tasked with risk stratifying their patients, both formally and informally, but recent data have called into question the value of clinician gestalt and the problem of both provider hubris and either implicit or explicit bias. ${ }^{90}$ In the case of this study, provider assessment may be a powerful tool for intervention with little harmful side effect beyond social resource utilisation. Future studies may seek to include not only providerbased assessments, but patient-based assessments as well. Providers rarely ask patients specifically if their social needs are being met on discharge. A more complete

\begin{tabular}{|c|c|c|c|c|}
\hline \multirow[b]{2}{*}{ Characteristic } & \multicolumn{2}{|l|}{72 hours } & \multicolumn{2}{|l|}{7 days } \\
\hline & Unadjusted OR & $95 \% \mathrm{Cl}$ & Unadjusted OR & $95 \% \mathrm{Cl}$ \\
\hline Homeless & 4.27 & 3.74 to 4.87 & 4.04 & 3.62 to 4.51 \\
\hline English & 2.56 & 2.11 to 3.12 & 2.43 & 2.09 to 2.83 \\
\hline Left AMA or prior to DC & 2.36 & 1.71 to 3.26 & 2.21 & 1.67 to 2.91 \\
\hline Lack of phone & 2.35 & 2.06 to 2.68 & 2.25 & 2.02 to 2.51 \\
\hline Psychiatric or substance use & 2.25 & 1.86 to 2.72 & 2.27 & 1.93 to 2.66 \\
\hline Age $\geq 40$ & 1.97 & 1.72 to 2.26 & 1.96 & 1.75 to 2.18 \\
\hline Male & 1.75 & 1.52 to 2.02 & 1.70 & 1.52 to 1.90 \\
\hline Initial LOS >249 $\min$ & 1.20 & 1.05 to 1.36 & 1.30 & 1.17 to 1.45 \\
\hline
\end{tabular}

AMA, against medical advice; DC, Discharge; LOS, length of stay. 
Table 5 Adjusted ORs and $95 \%$ Cls of return at 72 hours and 7 days from multivariable conditional regression modelling

\begin{tabular}{|c|c|c|c|c|}
\hline \multirow[b]{2}{*}{ Characteristic } & \multicolumn{2}{|l|}{72 hours $^{*}$} & \multicolumn{2}{|l|}{7 days $†$} \\
\hline & Adjusted OR & $95 \% \mathrm{Cl}$ & Adjusted OR & $95 \% \mathrm{Cl}$ \\
\hline Provider-assessed risk & 3.77 & 3.25 to 4.37 & 3.72 & 3.29 to 4.21 \\
\hline Homeless & 2.06 & 1.74 to 2.42 & 2 & 1.74 to 2.28 \\
\hline$\geq 1$ visit last 180 days & 1.91 & 1.63 to 2.23 & 2.1 & 1.85 to 2.38 \\
\hline English speaker & 1.43 & 1.17 to 1.76 & 1.42 & 1.21 to 1.68 \\
\hline Psychiatric or substance use & 1.25 & 1.01 to 1.53 & 1.29 & 1.08 to 1.54 \\
\hline Lack of phone & 1.21 & 1.03 to 1.40 & 1.2 & 1.06 to 1.37 \\
\hline Male & 1.14 & 0.98 to 1.33 & 1.15 & 1.01 to 1.30 \\
\hline
\end{tabular}

*Number of observations: 11 922; ROC: 0.7543.

†Number of observations: 11 922; ROC: 0.7490.

$\mathrm{ROC}$, receiver operating characteristic.

assessment of a patient's risk of ED return may ultimately incorporate not only demographic and clinical data, but also a provider's gestalt and a patient's own opinion of her own needs and capabilities.

\section{Limitations}

This study has several limitations. Our results are based on a convenience sample limited to $16.7 \%$ of all possible patient encounters. Clinical providers were not obligated to answer the question of whether they thought patients would re-present for emergency care, and thus may have actively decided not to answer in more difficult-to-assess cases, which risks a systematic bias and likely skews the estimates away from the null. The study validity is strengthened by the large and varied number of providers who participated and its embeddedness in the EHR. Additionally, this study was performed at a single hospital, with a specific patient population and significant rate of return visits to the ED. Results may not be generalisable to all emergency care settings. Similarly, this study lacks data on visit history at other hospitals within the follow-up period. Thus, discharges that resulted in ED presentations or admissions at other health facilities are not accounted for. This has been seen as a major limitation of prior studies. As a result, the conclusions most likely grossly underestimate the overall rate of ED revisits. Lastly, we were limited by a lack of clinical data in this study, including vital signs, clinical laboratory data and imaging results. Further studies that incorporate these variables may be warranted. Additionally, in this study, we also provide data on risk of ED revisits resulting in hospital admissions, though the question posed to providers did not solicit an estimation of that specific outcome. Further studies assessing clinician assessment of return visits resulting specifically in hospital admissions may be warranted.

\section{CONCLUSIONS}

Of all measured predictors of patient revisits to the ED that were included in this study, physician gestalt was the strongest. As in previous studies, homelessness and multiple prior visits remained strong predictors. Further programmes that include provider intuition could be used to support interventions aimed at strengthening the discharge process.

Acknowledgements The authors wish to thank the University of California San Francisco Professional Medical and Hospital Liability Program and the Clinical Practice Group for their support. The authors also thank Drs. Rebecca J Wolsky and Juan C Montoy for their suggestions in drafting this manuscript, and Dr. Alan Gelb for his support and advice.

Contributors Both authors (CBB and SF) contributed equally to the conceptualisation, funding, study investigation, methodology, administration, supervision, data curation and collection, and manuscript preparation and editing. CBB was largely (80\%) responsible for data analysis. CBB is responsible for the overall content as the guarantor and accepts full responsibility for the finished work and the conduct of the study, had access to the data, and controlled the decision to publish.

Funding University of California, San Francisco (Professional Medical and Hospital Liability Program. There is no grant number affiliated with this award)

Disclaimer The content is solely the responsibility of the authors and the decision to publish and the views expressed therein do not necessarily represent the official views of the funders.

Competing interests None declared.

Patient consent for publication Not required.

Ethics approval Ethical approval for this research was waived by the authors' institute IRB: UCSF; Study \#16-20510; Reference \#178771.

Provenance and peer review Not commissioned; externally peer reviewed.

Data availability statement Data are available upon reasonable request. Data are available upon reasonsable request to the corresponding author.

Supplemental material This content has been supplied by the author(s). It has not been vetted by BMJ Publishing Group Limited (BMJ) and may not have been peer-reviewed. Any opinions or recommendations discussed are solely those of the author(s) and are not endorsed by BMJ. BMJ disclaims all liability and responsibility arising from any reliance placed on the content. Where the content includes any translated material, BMJ does not warrant the accuracy and reliability of the translations (including but not limited to local regulations, clinical guidelines, terminology, drug names and drug dosages), and is not responsible for any error and/or omissions arising from translation and adaptation or otherwise.

Open access This is an open access article distributed in accordance with the Creative Commons Attribution Non Commercial (CC BY-NC 4.0) license, which permits others to distribute, remix, adapt, build upon this work non-commercially, and license their derivative works on different terms, provided the original work is properly cited, appropriate credit is given, any changes made indicated, and the use is non-commercial. See: http://creativecommons.org/licenses/by-nc/4.0/. 
ORCID iD

Corey B Bills http://orcid.org/0000-0002-3456-6008

\section{REFERENCES}

1 Wu C-L, Wang F-T, Chiang Y-C, et al. Unplanned emergency department revisits within 72 hours to a secondary teaching referral hospital in Taiwan. J Emerg Med 2010;38:512-7.

$2 \mathrm{Hu}$ SC. Analysis of patient revisits to the emergency department. $A m$ J Emerg Med 1992;10:366-70.

3 Bentley J, Meyer J. Repeat attendance by older people at accident and emergency departments. J Adv Nurs 2004;48:149-56.

4 Schuur JD, Venkatesh AK. The growing role of emergency departments in hospital admissions. N Engl J Med 2012;367:391-3.

5 Gabayan GZ, Asch SM, Hsia RY, et al. Factors associated with short-term bounce-back admissions after emergency department discharge. Ann Emerg Med 2013;62:136-44.

6 Barnett ML, Hsu J, McWilliams JM. Patient characteristics and differences in hospital readmission rates. JAMA Intern Med 2015;175:1803-12.

7 Brucker K, Duggan C, Niezer J, et al. Assessing risk of future suicidality in emergency department patients. Acad Emerg Med 2019;26:376-83.

8 Varney SM, Perez CA, Araña AA, et al. Detecting aberrant opioid behavior in the emergency department: a prospective study using the screener and Opioid Assessment for Patients with Pain-Revised $\left(\right.$ SOAPP $\left.^{\circledR}-\mathrm{R}\right)$, Current Opioid Misuse Measure (COMM) ${ }^{\mathrm{TM}}$, and provider gestalt. Intern Emerg Med 2018;13:1239-47.

9 Oliver G, Reynard C, Morris N, et al. Can emergency physician gestalt "Rule In" or "Rule Out" acute coronary syndrome: validation in a multicenter prospective diagnostic cohort study. Acad Emerg Med 2020;27:24-30.

10 Wells PS, Anderson DR, Rodger M, et al. Excluding pulmonary embolism at the bedside without diagnostic imaging: management of patients with suspected pulmonary embolism presenting to the emergency department by using a simple clinical model and D-dimer. Ann Intern Med 2001;135:98-107.

11 Sklar DP, Crandall CS, Loeliger E, et al. Unanticipated death after discharge home from the emergency department. Ann Emerg Med 2007:49:735-45.

12 Gunnarsdottir OS, Rafnsson V. Death within 8 days after discharge to home from the emergency department. Eur J Public Health 2008;18:522-6.

13 Kefer MP, Hargarten SW, Jentzen J. Death after discharge from the emergency department. Ann Emerg Med 1994;24:1102-7.

14 Guttmann A, Schull MJ, Vermeulen MJ, et al. Association between waiting times and short term mortality and hospital admission after departure from emergency department: population based cohort study from Ontario, Canada. BMJ 2011;342:d2983.
15 Pham JC, Kirsch TD, Hill PM, et al. Seventy-two-hour returns may not be a good indicator of safety in the emergency department: a national study. Acad Emerg Med 2011;18:390-7.

16 Gabayan GZ, Derose SF, Asch SM, et al. Patterns and predictors of short-term death after emergency department discharge. Ann Emerg Med 2011;58:551-8.

17 Lederer DJ, Bell SC, Branson RD, et al. Control of confounding and reporting of results in causal inference studies. guidance for authors from editors of respiratory, sleep, and critical care journals. Ann Am Thorac Soc 2019;16:22-8.

18 Duseja R, Bardach NS, Lin GA, et al. Revisit rates and associated costs after an emergency department encounter: a multistate analysis. Ann Intern Med 2015;162:750-6.

19 Gaieski DF, Agarwal AK, Mikkelsen ME, et al. The impact of ED crowding on early interventions and mortality in patients with severe sepsis. Am J Emerg Med 2017;35:953-60.

20 Hoot NR, Aronsky D. Systematic review of emergency department crowding: causes, effects, and solutions. Ann Emerg Med 2008;52:126-36.

21 Weinick RM, Burns RM, Mehrotra A. Many emergency department visits could be managed at urgent care centers and retail clinics. Health Aff 2010;29:1630-6.

22 Steiner C, Barrett M, Hunter K. Hospital readmissions and multiple emergency department visits, in selected states, 2006-2007. In: HCUP Statistical Brief \#90. Rockville, MD: Agency for Healthcare Research and Quality, 2010. http://www.hcup-us.ahrq.gov/reports/ statbriefs/sb90.pdf

23 Fuda KK, Immekus R. Frequent users of Massachusetts emergency departments: a statewide analysis. Ann Emerg Med 2006;48:16. e1-16.e8.

24 Hunt KA, Weber EJ, Showstack JA, et al. Characteristics of frequent users of emergency departments. Ann Emerg Med 2006;48:1-8.

25 Riggs JE, Davis SM, Hobbs GR, et al. Association between early returns and frequent ED visits at a rural academic medical center. Am $J$ Emerg Med 2003;21:30-1.

26 Johns Hopkins University, Armstrong Institute for Patient Safety and Quality. Improving the emergency department discharge process: environmental scan report. (prepared by Johns Hopkins University, Baltimore, MD, under contract No. HHSA 2902010000271. Rockville, MD: Agency for Healthcare Research and Quality, 2014.

27 Lam CN, Arora S, Menchine M. Increased 30-day emergency department Revisits among homeless patients with mental health conditions. West J Emerg Med 2016;17:607-12.

28 Gao K, Pellerin G, Kaminsky L. Predicting 30-day emergency department revisits. Am J Manag Care 2018;24:e358-64.

29 Meldon SW, Mion LC, Palmer RM, et al. A brief risk-stratification tool to predict repeat emergency department visits and hospitalizations in older patients discharged from the emergency department. Acad Emerg Med 2003;10:224-32.

30 Ashburn NP, Stopyra JP, Mahler SA. News from lake Wobegon ... clinician gestalt Debunked? Acad Emerg Med 2020;27:80-2. 